\title{
Analysis of Innovation Performances of European Union Member Countries
}

\author{
Asst. Prof. Dr. Miraç Eren (Ondokuz Mayıs University, Turkey) \\ Assoc. Prof. Dr. Selahattin Kaynak (Ondokuz Mayıs University, Turkey)
}

\begin{abstract}
Together with the transition from the industrial society to the information society, Innovation at the forefront of the countries' development arguments has strategic significance for companies, industries, and countries and it is emerging as the main element of being in the market. Also, Innovation has vital importance in determining the policies of countries because of increasing social welfare and living standards of individuals. Countries having effective innovation policies and systems are rapidly advancing in the development race. Even in countries with low innovation performance, demand for innovative products and services are high. According to the Lisbon Strategy, it is important to know the innovation performances of the member countries of the European Union, which see the innovation as the basic element of economic growth, and to measure their activities. For these reasons, the purpose of this research is to analyze the innovation performances of the EU member countries. So, Data Envelopment Analysis (DEA) to measure the performance of each member country against the other member countries in the group consisting of European Union countries was considered. Therefore, the variables that are used in determining the level of innovation of the member states of the European Commission were respectively considered as Input Variables (Human Research, Research Systems, Finance, and Support) and Output Variables (Innovators, Economic effects). Tone (2001)'s Slack-Based Model and Lotfi \& Poursakhi (2012)'s dynamic DEA Model was considered together to measure the efficiency of the countries in few periods instead of a single period.
\end{abstract}

\section{Introduction}

The innovation process defined as converting scientific knowledge into products with a market value has become a necessity for countries in today's economy that global competition is experienced as intense. Countries aim to improve the citizen's living standards and quality with all kinds of innovative activities. Decision makers and policy makers also make an effort to the establishment of this culture in the common ground by moving the innovation process.

All kinds of improvements reducing production costs, increasing productivity, providing to meet changing consumer demands in optimal level, and leading a positive contribution to social life are only possible with innovation. The innovation is the main component of the economic structure of the information society and a determinant of the competitiveness of companies. So, its importance is steadily increasing.

Innovation is important and necessary not only for all size of companies and industries but also for all economic decision-making units. The countries using their resources efficiently by the effective innovation policies and providing the economic growth will gain advantages for global competition.

Innovative activities provide a new perspective on the existing markets through some changes and transformations in conjunction with uncovering new markets (Kim and Pennings, 2009). In the studies taking into account criteria such as the sales volume, export, growth, the total employment and investment return for the measurement of the success performance of countries, it is stated that those who perform the innovative activities is provided relatively better performance according to those who not perform (Kemp, et. al, 2003).

It is necessary to have a country profile that exhibits good performance with a high innovation level, achieves competitive advantage, exhibits innovative products, and dominates technology transfer, to be in the determinant position in full membership process to the EU. In the literature, various studies examining the relationship between the innovation in macro and micro level, economic growth, firm performance, and competitive advantage have been conducted. One of the first economists emphasizing the importance of innovations in economic growth in studies carried out at the macro level is Schumpeter (1943). Domar (1946), Solow (1956), Romer (1986, 1990, 1994) who pioneered the endogenous growth theory, and Lucas (1988) have made studies concerning with the impact of innovation and technology in economic growth.

Most of the work done at the micro level is related with how and at what level the performances of the firm is affected. According to the findings of some study, Innovation provides a positive contribution to the economic performance of enterprises and industries (Baregheh, et. al, 2014; Diederen, et. al, 2002; Favre, et. al, 2002; Geroski, 1989, Hassan, et. al, 2013; Mohnen and Kleinknecht, 2002; Roper, et. al, 2008; Therrien, et. al, 2011; Wong, et. al, 2005).

In the study, it was considered Data Envelopment Analysis to measure the performance of each member country against the other member countries in the group consisting of European Union countries. For this purpose, the variables that are used in determining the level of innovation of the member states of the European Commission have been considered. So that, firstly, Dynamic DEA model taking into account, an alternative Dynamic Slack- 
Based Model is developed, called DSBM was expressed in the part of the methodology. Afterward, the manner that the levels of innovation of the member states of the EU were determined using Input and output variables utilized by the European Commission for the measurement of innovative activity is shown in the application section.

\section{Methodology}

In production environments that include a broad range of income and outcome, a nonparametric method DEA is used for productivity measurement. In literature, the term DEA is first used in the study of Charnes, Cooper, and Rhodes (CCR) dated in 1978. CCR aims to assign weights to the incomes and outcomes completing the production of the analyzed units through linear programming and to estimate a limit consisting units showing the best performance in the observation cluster. When observed decision units do not make production in optimal scale, which means, in the case of profits variable according to scale, CCR models fall behind in technical effectiveness measurement because of not being able to measure scale effectiveness due to their structure. BCC model of Banker Charnes and Cooper in 1984 developed in order to measure technical effectiveness under the assumption of profit variable according to scale, by separating technical effectiveness into its components as scale efficiency and pure technical efficiency, showed that technical effectiveness is equal to the multiplication of these two components (Cooper, et. al, 2007). Since 1978 until today many DEA analysis models are developed. One of developed these models is a slack based model (SBM). This model deals directly with the input excesses and the output shortfalls of DMUs. Furthermore, it is reference-set dependent, i.e. the measure is determined only by its reference set and is not affected by statistic over the whole data set. Tone (2001) demonstrated with the numerical example that is the compatibility of SBM with other measures and its potential applicability for practical purposes (Tone, 2001). However, SBM model for a single period measures the effectiveness of DMUs. At the end of a few periods to evaluate the effectiveness of DMU's Dynamic DEA models must be developed. To measure changes, the efficiency of DMUs at the end of multiple time periods have been proposed Dynamic DEA models at different times (Sengupta, 1996; Tone and Tsutsui, 2010 and Tone, 2001). Developed Dynamic DEA models have considered in the dynamic productions the relation between the inputs and outputs. Finally by the new dynamic DEA models has been developed by Lotfi \& Poursakhi, 2012.

In this study, as Tone (2001)'s SBM model and Lotfi \& Poursakhi (2012)'s dynamic DEA model taking into account, an alternative Dynamic Slack-Based Model is developed, called DSBM.

In the literature, some of the Dynamic DEA and SBM are: Emrouznejad (2003) provides an alternative DEA model that is based on several periods. This model is useful for DMUs with capital input. As a result of studies, the dynamic efficiency results should reflect reality better than those based on static DEA models, has found that (Emrouznejad, 2003). Emrouznejad and Thanassoulis (2005), is developed a method for assessing the performance of DMUs when their input-output levels are characterized by inter-temporal dependencies. This paper is suggested that dynamic model captures the efficiency better than the static model ((Emrouznejad and Thanassoulis, 2005). Amirteimoori (2006) is developed a new DEA with dynamic revenue efficiency. He is shown that a convex combination of these period measures makes up the efficiency of the whole periods (Amirteimoori, 2006). Tone and Tsutsui (2010) developed in the slack-based measure (SBM) framework, called dynamic SBM. They classify carry-overs into four categories, i.e. desirable (good), undesirable (bad), free and fixed. Their developed dynamic SDM models that can evaluate the overall efficiency of decision-making units for the whole terms as well as the term efficiencies (Tone and Tsutsui, 2010). Hosseinzadeh Lotfi and Poursakhi (2012) developed a model proposed for evaluating the relative efficiency of units which have time-dependent input-output. Their model was presented in which the time-dependent effects of undesirable inputs and outputs were considered, and time-dependent effects were formulated via time-dependent parameters (Lotfi and Poursakhi, 2012).

\subsection{An Alternative Dynamic Slack-Based Model-DSBM}

There are two types of efficiency measures, i.e., radial and non-radial. The CCR and BCC models present the radial approach. Its shortcoming is that it neglects the non-radial input/output slacks. The non-radial approach SBM deals with slack directly, but it neglects the radial characteristics of inputs and/or outputs. Slack based measure of efficiency (SBM) is a non-radial measure of efficiency. Thus, the SBM measure reflects not only the weak efficiency values in CCR-efficiency but also the other (slack) inefficiencies as well (Cooper, et. al, 2007). SBM model deals directly with the input excesses and the output shortfalls of the DMU concerned. SBM measures the effectiveness of DMUs at a single period. The single period optimization model is not suitable for performance evaluation even if these models can take into account the time change effect. For these cases, Dynamic DEA models have been developed. In this study, as Tone (2001)'s SBM model and Lotfi \& Poursakhi (2012)'s Dynamic DEA model taking into account, an alternative Dynamic Slack-Based Model is developed, called DSBM.

SBM by Tone (2001) is given below. In model, the production possibility set $\mathrm{P}$ is defined as

$$
P=\{((x, y) \mid x \geq X \lambda, y \leq Y \lambda, \lambda \geq 0)\},
$$


Where $\lambda$ is a nonnegative vector in $R^{n}$. In SBM is considered an expression for describing a certain DMU $\left(x_{0}, y_{o}\right)$ as,

$$
\begin{gathered}
x_{o}=X \lambda+s^{-}, \\
y_{o}=Y \lambda-s^{+},
\end{gathered}
$$

The vectors $\mathrm{s}^{-} \in \mathrm{R}^{\mathrm{m}}$ and $\mathrm{s}^{+} \in \mathrm{R}^{\mathrm{s}}$ indicate the input excess and output shortfall of this expression, respectively, and are called slacks. From the conditions $X>0$ and $\lambda \geq 0$, it holds $\mathrm{x}_{\mathrm{o}} \geq \mathrm{s}^{-}$. SBM is as follows (Tone, 2001).

[SBM]

$$
\begin{aligned}
\text { minimize } \rho & =\frac{1-(1 / m) \sum_{i=1}^{m} s_{i}^{-} / x_{i o}}{1-(1 / s) \sum_{r=1}^{s} s_{r}^{+} / y_{r o}} \\
\text { subject to } x_{i o} & =\sum_{j=1}^{n} x_{i j} \lambda_{j}+s_{i}^{-} \quad i=1, \ldots, m \\
y_{r o} & =\sum_{j=1}^{n} y_{i j} \lambda_{j}-s_{r}^{+} \quad r=1, \ldots, s \\
\lambda_{j}, s_{i}^{-}, s_{r}^{+} \geq 0 &
\end{aligned}
$$

$$
\text { Here, it holds } \quad 0 \leq \rho \leq 1 \text {. }
$$

The process of dynamic production studied in 1 to $n+1$ periods and showed as an index set $\mathrm{T}=\{1, \ldots, t+1\}$. For the desired time period $t$ in the observation window (i.e. $m$-period) depicts a time-dependent model of the production process where the inputs used in the period $t$ can be used in output production in the $t, t+1, \ldots, t+m$ periods (Lotfi and Poursakhi, 2012). Accordingly, to this developed DSBM model is given below;

[DSBM]

$$
\begin{aligned}
& \text { minimize } \rho=\frac{1}{T} \sum_{t=1}^{T}\left(\frac{1-(1 / m) \sum_{i=1}^{m} \frac{s_{i}^{t-}}{x_{i o}^{t}}}{1+(1 / s) \sum_{r=1}^{S} \frac{s_{r}^{t+}}{y_{r o}^{t}}}\right) \\
& \text { Subject to } \quad x_{i o}^{t}=\sum_{j=1}^{n} x_{i j}^{t} \lambda_{j}+s_{i}^{t-}, \quad i=1, \ldots, m \\
& y_{r o}^{t}=\sum_{j=1}^{n} y_{i j}^{t} \lambda_{j}-s_{r}^{t+}, \quad r=1, \ldots, s \\
& \lambda_{j}, s_{i}^{t-}, s_{r}^{t+} \geq 0
\end{aligned}
$$

\section{Application}

In the research, the variables that are used in determining the level of innovation of the member states of the European Commission have been considered. European Innovation Scoreboard provides a comparative assessment of the research and innovation performance of the EU Member States and the relative strengths and weaknesses of their research and innovation systems. It helps Member States assess areas in which they need to concentrate their efforts in order to boost their innovation performance. Input and output variables utilized by the European Commission for the measurement of innovative activity are:

Input Variables; Human Research, Research Systems, Finance and Support

Output Variables; Innovators, Economic effects

Terms; between 2010-2014 years

A brief depiction of the content of these variables may be useful. According to this,

\section{Input Variables}

Inputs capture the main drivers of innovation performance external to the firm and differentiate between three innovation dimensions. 
The Human resources dimension includes three indicators and measures the availability of a high-skilled and educated workforce. Indicators; New doctorate graduates, Population completed tertiary education and Youth with upper secondary level education.

The Open, excellent and attractive research systems dimension includes three indicators and measures the international competitiveness of the science base. Indicators; International scientific co-publications, Scientific publications among top $10 \%$ most cited and Non-EU doctorate students.

The Finance and support dimension includes two indicators and measures the availability of finance for innovation projects and the support of governments for research and innovation activities. Indicators; Public R\&D expenditure and Venture capital.

Output Variables

Outputs capture the effects of enterprises' innovation activities and differentiate between two innovation dimensions.

The Innovators dimension includes three indicators and measures the number of enterprises that have introduced innovations onto the market or within their organisations, covering both technological and non- technological innovations and the presence of high-growth enterprises. Indicators; SMEs introducing product or process innovations, SMEs introducing marketing/organisational innovations and Employment in fast-growing enterprises.

The Economic effects dimension includes five indicators and captures the economic success of innovation in employment, exports, and sales due to innovation activities. Indicators; Employment in knowledge-intensive activities, Medium and high tech product exports, Knowledge-intensive services exports, Sales of new to market and new to firm innovations and License and patent revenues from abroad.

\begin{tabular}{lccllllr}
\hline Countries & Result & Countries & Result & Countries & Result & Countries & Result \\
\hline Belgium & 1.000 & Greece & 1.000 & Luxembourg & 0.271 & Romania & 0.623 \\
Bulgaria & 0.463 & Spain & 1.000 & Hungary & 1.000 & Slovenia & 1.000 \\
Czech Republic & 0.428 & France & 0.418 & Malta & 1.000 & Slovakia & 0.435 \\
Denmark & 1.000 & Italy & 0.429 & Netherlands & 1.000 & Finland & 1.000 \\
Germany & 1.000 & Cyprus & 1.000 & Austria & 0.385 & Sweden & 0.407 \\
Estonia & 0.485 & Latvia & 1.000 & Poland & 0.439 & United Kingdom & 0.386 \\
Ireland & 1.000 & Lithuania & 1.000 & Portugal & 0.627 & Croatia & 0.366 \\
\hline
\end{tabular}

Table 1. Dynamic Slack Based Model-DSBM Efficiency Results

According to European Innovation Scoreboard ranking results, which the innovation performances of European Union member states have been annually published, the countries is classified as Innovation Leaders, Strong Innovators, Moderate Innovators and Modest Innovators (Europe, 2008). Cyprus, Greece, Hungary, Latvia, Lithuania, and Malta are among the best-performing countries in this study while these according to the European Innovation Scoreboard ranking results are located in the class of the moderated innovators. Similarly, Sweden is located in the class of the Innovation Leaders, and Luxembourg, United Kingdom, France, and Austria are located in the class of Strong Innovators. According to the findings, they have not performed well.

\section{Conclusions}

The European Innovation Scoreboard ranking results, which the innovation performances of European Union member states have been annually published, are obtained by considering variables as Firm investments, LinkagesEntrepreneurship-Intellectual Assets, Human Research, Research Systems, Finance and Support, Innovators, Economic effects. In this study, it was considered Data Envelopment Analysis to measure the performance of each member country against the other member countries in the group consisting of European Union countries. Based on this efficiency analysis having inputs-outputs, Human Research, Research Systems, Finance and Support variables were taken as inputs, and Innovators, Economic effects variables were considered as the outputs. Firm Investments, Linkages-Entrepreneurship-Intellectual Assets variables were excluded from the study because these do not refer to any input or output. In addition, to measure the efficiency of the countries (which are called as DMU) in few periods instead of a single period, Tone (2001)'s Slack-Based Model model and Lotfi \& Poursakhi (2012)'s dynamic DEA model was considered together. The developed model was called as Dynamic Slack-Based Model-DSBM. According to DSBM results, it was observed that the overall innovation efficiencies of EU member countries between 2010-2014 were similar largely with the European Innovation Scoreboard ranking results measuring the annual innovation performance. In addition, Cyprus, Greece, Hungary, Latvia, Lithuania, and Malta that is located in the class of the moderated innovators (that is, low-level innovators) according to European Innovation Scoreboard ranking results are among the best-performing countries in this research. this situation 
shows that these countries use their innovative sources in an optimal way (that they better evaluate innovative inputs).

\section{References}

- Amirteimoori, 2006. "Data envelopment analysis in dynamic framework", Applied mathematics and computation, 181, p. 21-28.

- Baregheh, et. al, 2014. "Towards an integrative view of innovation in food sector SMEs", The International Journal of Entrepreneurship and Innovation, 15, p. 147-158.

- Diederen, et. al, 2002. "Innovation and farm performance: the case of Dutch agriculture. In Innovation and Firm Performance”, (pp. 73-85). Palgrave Macmillan UK.

- Domar, 1946. “Capital Expansion, Rate of Growth, and Employment”, Econometrica, 14, p. 137-147.

- Emrouznejad, 2003. "An alternative DEA measure: a case of OECD countries”, Applied Economics Letters, 10, p. 779-782.

- Emrouznejad and Thanassoulis, 2005. "A mathematical model for dynamic efficiency using data envelopment analysis", Applied mathematics and computation, 160, p. 363-378.

- $\quad$ Europe, 2008. European innovation scoreboard 2007: Comparative analysis of innovation performance. Office for Official Publications of the European Communities.

- Favre, et. al, 2002. "The effect of spillovers and government subsidies on R\&D, international R\&D cooperation and profits: evidence from France", In Innovation and Firm Performance, Springer, p. 201-224.

- Geroski, 1989. "Entry, innovation and productivity growth", The review of Economics and Statistics, p. 572-578.

- Hassan, et. al, 2013. "Effects of innovation types on firm performance: an empirical study on Pakistan's Manufacturing Sector”, Pakistan Journal of Commerce and Social Sciences, 7, p. 243-262.

- Kemp, et. al, 2003. Innovation and firm performance (No. H 200207). Zoetermeer, The Netherlands: EIM.

- Kim and Pennings, 2009. "Innovation and strategic renewal in mature markets: A study of the tennis racket industry", Organization Science, 20, p. 368-383.

- Kleinknecht and Mohnen, 2001. Innovation and firm performance: Econometric explorations of survey data. Springer.

- $\quad$ Lotfi and Poursakhi 2012. "A Mathematical Model for Dynamic Efficiency Using Desirable and Undesirable Input-Output”, Applied Mathematical Sciences, 6, p. 141-151.

- Lucas, 1988. "On the Mechanics of Economic Development”, Journal of Monetary Economics, 22, p. 3-42.

- Romer, 1986. “Increasing Returns and Long-Run Growth”, Journal of Political Economy, 94, p. 1002-1037.

- Romer, 1990. "Endogenous Technological Change”, Journal of Political Economy, 98, p. 71-102.

- Romer, 1994. “The Origins of Endogenous Growth”, Journal of Economic Perspectives, 8, p. 3-22.

- $\quad$ Roper, S., Du, J., \& Love, J. H. (2008). Modelling the innovation value chain. Research policy, 37(6), 961 977.

- Schumpeter, 1943. The Theory of Economic Development, Cambridge, Mass.: Harvard University Press (originally published in German in 1911; reprinted by Transaction Publishers, New Brunswick, New Jersey in 1997).

- Sengupta, 1996. "Systematic measures of dynamic Farrell efficiency", Applied Economics Letters, 3, p. 91 94.

- Solow, 1956. A Contribution to the Theory of Growth (reprinted). In: Sen, A. ed., Growth economics. Selected Readings, 161-192. Penguin, Harmondsworth.

- Therrien, et. al, 2011. "Innovation novelty and (commercial) performance in the service sector: A Canadian firm-level analysis", Technovation, 31, p. 655-665.

- Tone, 2001. “A slacks-based measure of efficiency in data envelopment analysis”, European journal of operational research, 130, p. 498-509.

- Tone and Tsutsui 2010. "Dynamic DEA: A slacks-based measure approach”, Omega, 38, p. 145-156.

- Wong, et. al, 2005. "Entrepreneurship, innovation and economic growth: Evidence from GEM data”, Small business economics, 24, p. 335-350. 